\title{
SEíS: A semantic-based system for integrating building energy data
}

\author{
SEíS: Sistema basado en tecnologías semánticas para integrar \\ la información energética de los edificios
}

$\underline{\text { L. Madrazo }}^{(*)}$, M. Massetti ${ }^{(*)}$, A. Sicilia ${ }^{(*)}$, G. Wadel ${ }^{(*)}$, M. Ianni ${ }^{(*)}$

\begin{abstract}
Access to reliable energy related data is a fundamental factor when taking decisions that help to improve the energy efficiency of buildings. The increase in the amount of data we have available has led to the need to develop information systems that facilitate the analysis of such data to the agents which are present throughout the building life cycle, from the design phase to maintenance. Semantic web technologies provide a solution to interlink distributed data sources. This requires the construction of shared vocabularies (i.e. ontologies) which capture the meaning that users give to the data and facilitate access to them. As yet there are no consolidated methods to build these vocabularies. This article presents the methodology developed to create SEís, an energy information system that uses semantic technologies to integrate energy related data and to facilitate services to the different agents involved throughout the stages of the building life cycle.
\end{abstract}

Keywords: Building energy efficiency; energy information systems; semantic technologies; ontologies.

\section{RESUMEN}

El acceso a los datos relacionados con la energía es un factor fundamental para tomar decisiones que ayuden a mejorar la eficiencia energética de los edificios. El incremento de la cantidad de datos disponibles ha llevado a la necesidad de desarrollar sistemas de información que faciliten el análisis de los mismos a los agentes que participan a lo largo del ciclo de vida del edificio, desde el diseño hasta el mantenimiento. Las tecnologías de la web semántica proporcionan una solución para interconectar fuentes de datos distribuidas. Esto requiere la construcción de vocabularios compartidos (i.e. ontologías) que capten el significado que le dan los usuarios a la información y faciliten el acceso a los datos. No existen aún métodos consolidados para construir estos vocabularios. En este artículo se presenta la metodología desarrollada para crear SEíS, un sistema de información energética que utiliza tecnologías semánticas para integrar datos energéticos y facilitar servicios a los agentes que intervienen a lo largo de las fases del ciclo de vida del edificio.

Palabras clave: Eficiencia energética en edificios; sistemas de información energética; tecnologías semánticas; ontologías.

(*) ARC Engineering and Architecture La Salle - Ramon Llull University, Barcelona (Spain). Persona de contacto/Corresponding author: madrazo@salleurl.edu (L. Madrazo)

Cómo citar este artículo/Citation: Madrazo, L., Massetti, M., Sicilia, A., Wadel, G., Ianni, M. (2015). SEíS: A semantic-based system for integrating building energy data. Informes de la Construcción, 67(537): eo6o, doi: http://dx.doi.org/10.3989/ic.13.048.

Licencia / License: Salvo indicación contraria, todos los contenidos de la edición electrónica de Informes de la Construcción se distribuyen bajo una licencia de uso y distribución Creative Commons Reconocimiento no Comercial 3.o. España (cc-by-nc). 


\section{INTRODUCTION}

In order to adopt the appropriate measures to improve the energy efficiency of existing and new buildings, the different agents involved -owners and occupants, energy providers and facility managers, design teams and consultants, administration and private developers- need reliable information concerning buildings' energy performance. In fact, having an "imperfect information" about the energy performance of buildings is considered by an Intergovernmental Panel on Climate Change (IPCC) report as one of the main obstacles to be overcome since "in the vast majority of countries detailed end-use data is poorly collected or reported publicly" which results in "a severe lack of robust, comprehensive, detailed and up-to-date bottom-up assessments of GHG reduction opportunities and associated costs in buildings, worldwide" (1).

Having information about the real performance of buildings is not only necessary in order to upgrade the building stock, but it is also needed to make more effective decisions at the design stage. As a general rule, buildings do not tend to perform in practice as they were intended to. This also occurs with regard to energy efficiency. To bridge this gap between design and performance, the need for a "standardized method for documenting and communicating information about the intended and the actual performance of a building" (2) has been already pointed out and solutions based on the application of IFC standards have been proposed. Such methods would enable the various agents involved in the improvement of energy efficiency of buildings -throughout all the different stages of the building life cycle, from design to construction and refurbishment- to adopt more efficient measures in their respective decision realms.

Energy related data are increasingly available today. Data on consumption, monitoring, simulations, weather forecast and energy supply, for example, can be available either as proprietary data or as open data (linked data, linked open data). In this context the need to have a combined access to the distributed sources of data has become increasingly important. Semantic technologies provide a solution to the problem of accessing multiple data sources. Their application requires the design of ontologies that capture the meaning of the data and facilitate access to it. As stated in the widely acknowledged definition of ontology from Gruber (3), an ontology is "a formal and explicit specification of a shared conceptualization" consisting of vocabulary concepts and their relationships. Building an ontology that provides a shared representation of a field of knowledge is difficult because each domain expert has a particular view of reality. At this point, there are no well-established methods to create ontologies so they have to be created through a craft process that requires specific strategies for each particular case.

Nowadays, the application of Semantic Web technologies in the field of building energy is still in its infancy. Although we can find applications of semantic technologies to specific domains related to energy efficiency in buildings -operation, interoperability, smart grid - not much work has been done with regard to the modelling of the energy data generated by different applications throughout the whole building life cy- cle. With this respect, a precedent is the research project InTUBE (4), which is an early attempt to create an information platform that uses semantic web standards to link building, simulation and performance data. More recently, Murray (5) has postulated the use of semantic web technologies to interlink different energy domains - policies, supply and demand, facility management and building design- as a way of reducing energy use.

Therefore, the design and development of semantic information systems that can help to improve the energy efficiency of buildings is an incipient area of research. There are no consolidated methods to create building energy information systems using ontologies. Neither are there -to be best of our knowledge- systems that facilitate services based on the combined access to the data generated over the different stages of the building life cycle. This article presents the methodology developed to create SEíS, a Semantic Energy Information System that integrates energy related data and facilitates services to different agents involved in the design, construction and maintenance of buildings.

\section{ACCESSING ENERGY DATA ALONG THE BUILDING LIFE CYCLE}

The lack of adequate information on energy affects all the stages of the building life cycle, but it is particularly negative at the initial phase when the decisions that have the greatest impact on the performance of buildings are made. This lack of information makes it difficult for the design team -architects and engineers - to assess the actual impact of their design decisions on the energy performance of buildings without the aid of experts. Furthermore, having consistent and standardized information from the whole building life cycle would help to create more sustainable buildings by applying the enhanced Life Cycle Energy Assessment (LCEA) (6), using tools such as the Environmental Product Declarations (EPD) $(7)^{1}$.

With regard to the improvement of the existing building stock, it is necessary to have information on the energy performance of the existing buildings to spot the areas of intervention with the largest potential for improvement: urban or rural locations, typological and physical characteristics, equipment level and state of conservation. Having this information available would help policy makers and building and energy companies to identify and prioritize the most effective and efficient ways of improving the energy efficiency of the building stock. As shown in precedent studies (9), the frequent measurement of indicators such as equipment, energy consumption and occupants' behaviour of buildings, becomes necessary in order to have reliable information on energy building performance.

To sum up, a reliable and continuous data collection along the different stages of the building life cycle -from design to construction, during operation and refurbishment- is required to improve the decision making process at the design stage and to help all agents involved to make better informed decisions concerning the improvement of energy performances of new and existing buildings (10).

\footnotetext{
According to the authors of this report, the integration of communication tools would help to improve EPD, by using consistent databases and standardized formats enabling benchmarking and monitoring progress (7).
} 


\subsection{Collecting and systematizing energy data}

In recent years, there have been a number of initiatives conducted by research projects and organizations with the aim of facilitating the access to energy-related data. For example, the Energy Guide for Houses (EGH) is a management information tool and a central database to store and retrieve residential energy evaluations delivered across Canada. The collected information is used by energy advisors to perform detailed house energy efficiency evaluations and recommend measures to improve the energy efficiency (11). More recently, the research project Datamine (12) has created a data structure to exchange information regarding the energy performance of buildings, using the information of energy certificates with the purpose of improving the knowledge about the energy performance of the building stock. Its follower, Tabula (13), has published a database of building typologies from different European countries, together with a tool to calculate energy consumption values.

In addition, some energy data portals have been created to provide information about buildings with the purpose of identifying best practices and of facilitating the exchange of knowledge. One such project worth mentioning is the SIRENA project (14), developed for the Lombardy region, which provides detailed information for decision makers including a library of case studies; and the Minergie database (15) of buildings which complies with the required level of comfort and energy consumption.

The above-mentioned on-line databases and others facilitate energy information on the building stock and, in some cases, provide tools to operate the data. Their limitation, however, is that they only can work with the data that are managed in the portal. More recent projects such as REEGLE (16) make use of Linked Open Data (LOD) technologies to access energy related data, obtained from open sources (17). Similarly, the Open Energy Information (OpenEI) (18) online platform provides a free and open access to energy-related data, models, tools, and to information which is made available via Linked Open Data standards.

The combined access to data from distributed sources using Linked Open Data technologies could result in energy information systems that would help to improve energy efficiency in buildings. Having access to this enhanced information would help to improve decision making, by avoiding repetitions in data collection and analysis - a process which at present has to be repeated every time a new project starts- and to build a shared knowledge base, originating from the information gathered over time.

\subsection{Interlinking the phases of the building life cycle}

As often claimed, the design and building process is segmented and discontinuous. At each stage, decisions are made by actors that have different expertise and that bear different value criteria on the overall nature and functionalities of the building (19). In addition, different kinds of information are handled at each stage, embodying the values and knowledge that experts have of their respective domains. Usually, design decisions are made at a particular state of the process based on non-existent or incomplete information and therefore, re- placed with assumptions and rules of thumb, derived from the personal experience of the expert.

For instance, certification tools used at the design phase for the calculation of building performance are based on standard occupation profiles that do not correspond to the occupants' behaviour. Examples of monitored buildings show that real occupation profiles may be quite different from assumptions based on standard profiles (20). This is a typical problem brought about by the lack of connection between design and performance data.

A completely new scenario would arise if reliable information was easily available to the different actors operating in the life cycle of a building, in the form required for a particular task. For instance, a facility manager may wish to know the lowest acceptable set point temperatures for heating in a particular building type and climate conditions; an owner, the time to pay back the investment in improving the building; and a local authority the post-occupancy energy consumption with regard to the comfort level. Nowadays, it is possible to obtain this information from separate data sources. However, data remain unrelated since they have been produced with different methodologies and tools, presents incompatible formats or units, uneven aggregation levels, and are tied to specific stages of a life cycle.

With existing ICTs it is possible to create an energy information system that overcomes these difficulties by interlinking the distributed data sources and providing a unified access to them.

\subsection{Creating integrated information systems}

The flow of information across the different stages and among the various agents would be facilitated by an integrated energy information system. With such systems, links between the different stages and stakeholders would be created as a result of sharing of the information from different sources. For instance, a design team working on a refurbishment project might need information from an energy certificates database to identify benchmarks for other buildings of the same type and in similar climate conditions. In this case, energy consumption values, obtained from existing buildings, may be used as reference values for buildings under refurbishment. In this way, connecting the different stages throughout the information flow would contribute to bridging the gap between design and performance.

Integrated information systems would facilitate the transformation of data into valuable information for a stakeholder acting at a particular stage of the building life cycle. Modelling the flow of energy data through the building life cycle and facilitating access to it in different formats and to different stakeholders would give rise to innovative services which today are not feasible or even imaginable (Figure 1). For instance, energy specialists would be able to implement energy performance benchmarking on the energy information systems to answer customized demands in real-time with updated data. Moreover, learning from examples of efficient buildings could be provided by the information facilitated by the system: design patterns could be identified based on combined analysis of design and performance data. Implementing these innovative services, however, might require information that is still not fully available nowadays. 


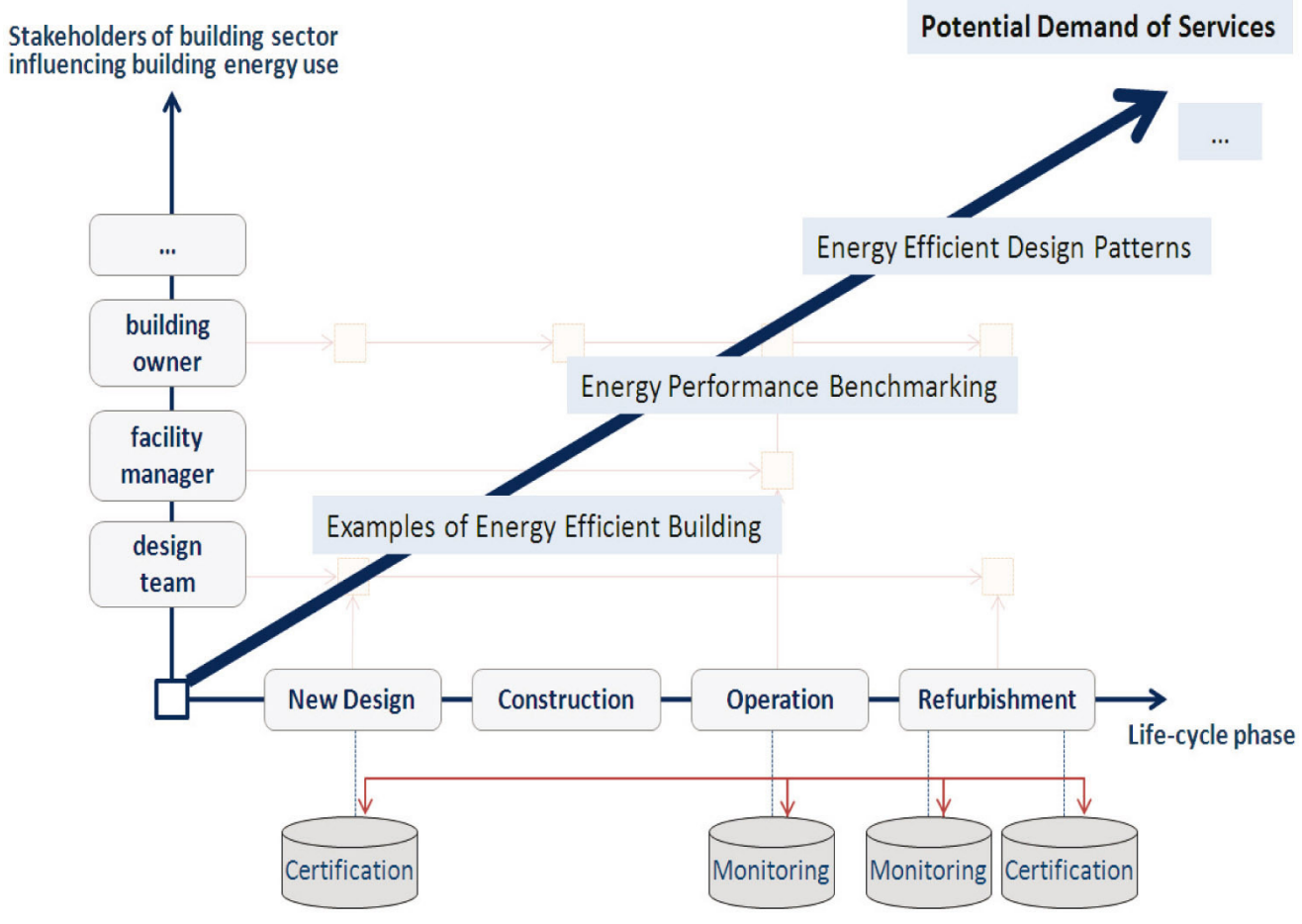

Figure 1. Innovative services connecting data sources and stakeholders.

Today, different barriers hamper the creation of such integrated energy information systems. Some of them have to do with the division of design knowledge into specialized compartments, whereby each one corresponds to a particular professional skill. The lack of connection between stages -from design to operation- is also due to this knowledge specialization. Other kinds of difficulties, however, stem from the information itself: the difficulty to access energy related information in the appropriate format in the moment that it is needed.

\section{CREATING A SEMANTIC ENERGY INFORMATION SYSTEM}

In order to design and build an integrated energy system as envisioned in the previous section we have turned to semantic technologies. These technologies facilitate the interlinkage between multiple data sources based on a common vocabulary of terms and relationships known as ontologies. The following section describes the process followed to design and implement SEíS, a semantic energy information system to provide access to building energy data.

The process to build the system has developed along two parallel tracks: a) A requirements capture process to identify the needs of the potential users of the system in terms of data and services. This process was carried out by means of use cases that encapsulated data, services and users in a particular application case. b) The creation of an energy model using ontologies that encompass the different data sources identified in the use cases. The energy model contains the terms of the shared vocabulary and their relationships (Figure 2).

\subsection{Capturing users' requirements}

At the start, some of the representative stakeholders involved at different stages of the building life cycle were identified. Their selection was guided by the experience and knowledge of the authors. They were represented by an architecture design team (Frutos - Sanmartin Arquitectos), a public administration department in charge of the collection of building energy certificates (the Catalan Institute of Energy, ICAEN), and a research group involved in building energy assessment, monitoring and management (Beegroup, CIMNE). This limited number of stakeholders was considered representative enough to carry out the process of knowledge and information capturing which was the first step in the construction of an ontology spanning through several stages of the building lifecycle.

In a series of interviews, we presented the selected stakeholders with a vision of the functionalities of the system to be developed. They were asked about the data they needed to perform their activities and the difficulties they had accessing it. Based on their feedback and the previous knowledge of the authors, we elaborated Table 1 with a more detailed list of users involved in the building life cycle, the data they required at each stage, and the actions they performed.

The table helped to identify the gaps that currently impede the flow of information across the building life cycle in which various activities are performed by different actors and in different stages of the building life cycle. This systematization of activities and actors prepared the ground for the next step of the knowledge capturing process that was to model use cases.

In order to proceed with the system development, some of the most relevant actors, phases and activities which had an impact on the decisions concerning the building energy performance during the building life cycle were identified and their interactions encapsulated in use cases.

In the context of this research, a use case is a conceptual model that relates users, data and services at a particular stage of 
Table 1. Activities of stakeholders along the stages of the life cycle.

\begin{tabular}{|c|c|c|c|c|c|}
\hline & \multicolumn{4}{|c|}{ Project life cycle } & \multirow{3}{*}{ Other } \\
\hline & \multicolumn{2}{|c|}{ Design } & \multirow{2}{*}{ Construction } & \multirow{2}{*}{ Use } & \\
\hline & Initial design & Final design & & & \\
\hline $\begin{array}{l}\text { Design } \\
\text { team }\end{array}$ & $\begin{array}{l}\text { SearchExamples, } \\
\text { IdentifyBenchmarks, } \\
\text { DetectPatterns, } \\
\text { DetectSimDeviation, } \\
\text { VerifyProjectHp, } \\
\text { GetRegulation, } \\
\text { PredicEnergyPerf }\end{array}$ & $\begin{array}{l}\text { SearchExamples, } \\
\text { IdentifyBenchmarks, } \\
\text { GetOpProfiles, } \\
\text { DetectPatterns, } \\
\text { DetectSimDeviation, } \\
\text { VerifyProjectHp, } \\
\text { GetRegulation, } \\
\text { PredicEnergyPerf }\end{array}$ & & & \\
\hline $\begin{array}{l}\text { Facility } \\
\text { manager }\end{array}$ & & & & $\begin{array}{l}\text { SearchExamples, } \\
\text { IdentifyBenchmarks, } \\
\text { GetOpProfiles, } \\
\text { DetectPatterns, } \\
\text { GetRegulation, } \\
\text { PredicEnergyPerf }\end{array}$ & \\
\hline $\begin{array}{l}\text { Energy } \\
\text { consultant }\end{array}$ & $\begin{array}{l}\text { SearchExamples, } \\
\text { IdentifyBenchmarks, } \\
\text { DetectPatterns, } \\
\text { DetectSimDeviation, } \\
\text { PredicEnergyPerf }\end{array}$ & $\begin{array}{l}\text { SearchExamples, } \\
\text { IdentifyBenchmarks, } \\
\text { GetOpProfiles, } \\
\text { DetectPatterns, } \\
\text { DetectSimDeviation, } \\
\text { VerifyProjectHp, } \\
\text { GetRegulation, } \\
\text { PredicEnergyPerf }\end{array}$ & & $\begin{array}{l}\text { SearchExamples, } \\
\text { IdentifyBenchmarks, } \\
\text { GetOpProfiles, } \\
\text { DetectPatterns, } \\
\text { DetectSimDeviation, } \\
\text { VerifyProjectHp, } \\
\text { GetRegulation, } \\
\text { PredicEnergyPerf }\end{array}$ & \\
\hline $\begin{array}{l}\text { Building } \\
\text { occupant }\end{array}$ & & & & $\begin{array}{l}\text { SearchExamples, } \\
\text { IdentifyBenchmarks, } \\
\text { DetectPatterns, } \\
\text { PredicEnergyPerf }\end{array}$ & \\
\hline $\begin{array}{l}\text { Building } \\
\text { owner }\end{array}$ & $\begin{array}{l}\text { SearchExamples, } \\
\text { IdentifyBenchmarks, } \\
\text { DetectPatterns, } \\
\text { GetRegulation, } \\
\text { PredicEnergyPerf }\end{array}$ & $\begin{array}{l}\text { SearchExamples, } \\
\text { IdentifyBenchmarks, } \\
\text { DetectPatterns, } \\
\text { GetRegulation, } \\
\text { PredicEnergyPerf }\end{array}$ & & $\begin{array}{l}\text { SearchExamples, } \\
\text { IdentifyBenchmarks, } \\
\text { DetectPatterns, } \\
\text { VerifyProjectHp, } \\
\text { GetRegulation, } \\
\text { PredicEnergyPerf }\end{array}$ & \\
\hline $\begin{array}{l}\text { Policy } \\
\text { maker }\end{array}$ & & & & & $\begin{array}{l}\text { IdentifyBenchmarks, } \\
\text { DetectPatterns, } \\
\text { GetOpProfiles, } \\
\text { PredicEnergyPerf }\end{array}$ \\
\hline $\begin{array}{l}\text { Public } \\
\text { administration }\end{array}$ & & & & $\begin{array}{l}\text { SearchExamples, } \\
\text { IdentifyBenchmarks, } \\
\text { DetectPatterns, } \\
\text { VerifyProjectHp, } \\
\text { PredicEnergyPerf }\end{array}$ & \\
\hline Researcher & & & & & $\begin{array}{l}\text { SearchExamples, } \\
\text { IdentifyBenchmarks, } \\
\text { GetOpProfiles, } \\
\text { DetectPatterns, } \\
\text { DetectSimDeviation, } \\
\text { VerifyProjectHp, } \\
\text { GetRegulation, } \\
\text { PredicEnergyPerf }\end{array}$ \\
\hline $\begin{array}{l}\text { Simulation tools } \\
\text { developers }\end{array}$ & & & & & $\begin{array}{l}\text { SearchExamples, } \\
\text { IdentifyBenchmarks, } \\
\text { GetOpProfiles, } \\
\text { DetectPatterns, } \\
\text { DetectSimDeviation, } \\
\text { VerifyProjectHp, } \\
\text { GetRegulation, } \\
\text { PredicEnergyPerf }\end{array}$ \\
\hline $\begin{array}{l}\text { Building } \\
\text { component } \\
\text { manufacturer }\end{array}$ & & & & & $\begin{array}{l}\text { GetOpProfiles, } \\
\text { DetectPatterns, } \\
\text { GetRegulation }\end{array}$ \\
\hline $\begin{array}{l}\text { Energy utility } \\
\text { company } \\
\text { (e.g. Gas) }\end{array}$ & & & & $\begin{array}{l}\text { IdentifyBenchmarks, } \\
\text { GetOpProfiles, } \\
\text { DetectPatterns, } \\
\text { GetRegulation, } \\
\text { PredicEnergyPerf }\end{array}$ & \\
\hline
\end{tabular}

\section{Activity}

SearchExamples

IdentifyBenchmarks

GetOpProfiles

DetectPatterns

DetectSimDeviation

VerifyProjectHp

GetRegulation

PredicEnergyPerf
Searching examples of building

Identifying performance benchmarks

Geting typical operational profiles

Detecting energy efficient design/operation patterns

Detecting simulation tools deviation trend

Verifying project hypothesis

Geting regulation constraints data

Predicting energy performance 
A) Capturing users' requirements

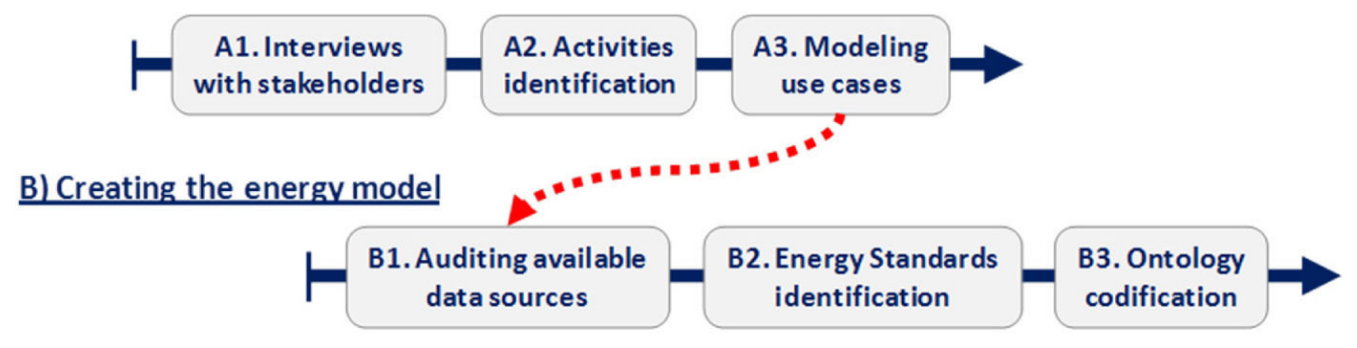

Figure 2. Development process of SEíS.

the working process. The purpose of a use case is twofold: to define the specifications of the information system that is going to be developed and to create a description of the energy model formalized as an ontology.

Four different use cases have been modelled following the same procedure:

- definition of the goals of the user, and the activities to achieve them

- identification of the information that the user needs to take actions to reduce energy consumption

- identification of the information sources which are used in current practice

- association of the information with the different stages of the building life cycle

- detection of the obstacles and limitations that prevent access to the information

- creation of new services which facilitate the information in the appropriate form

- identification of the data that new services require

The scope and characteristics of each use case are summarized as follows:

Use case 1. A design team working at the initial design phase of a new building

The user's profile is a small design team without advanced knowledge on energy efficiency. Their task is to design a low energy building. At the early design stage, they need to set energy performance goals and explore possible design solutions. To do this, they need:

- to look for performance benchmarks to set design goals in terms of energy efficiency

- to look for successful precedents which might serve as models to follow, indicating possible design solutions for similar design problems

- to understand the impact of their design decisions in terms of energy performance.

Typically, a design team obtains this information from several sources such as previous projects, databases, web pages, specialized journals, research and technical reports, consultants and colleagues. These information sources are heterogeneous and disperse and, therefore, difficult to reach. Furthermore, without the help of energy consultants, designers cannot adequately interpret some of the information they obtain. However, having access to the information and analysing it properly absorbs substantial resources from the project in terms of time and budget, as a whole.
Three services supported by the energy information system would help to overcome the obstacles and the limitations of the design team at the design stage:

- to provide examples of buildings for new building design

- to facilitate performance benchmarks for new building design

- to identify energy efficient design patterns

Use case 2. A facilities manager responsible for the operation of an existing building

The user is a facilities manager without advanced knowledge on how to operate a building and its equipment efficiently, in terms of energy performance. The goal is to improve the energy performance of a building, which means:

- to look for performance benchmarks of comparable buildings with similar building equipment.

- to look for precedents that might help to make decisions concerning changes in current operational settings and maintenance interventions.

- to estimate the impact of the changes made in current operational settings and maintenance interventions.

As in the previous case, nowadays a facility manager would have this information from several heterogeneous and disperse sources. The lack of a consolidated experience in energy- efficient operations of the facility manager would prevent him from identifying and exploiting the information. In particular, it is difficult to obtain energy monitoring data from existing buildings, information that may be especially relevant for a facility manager.

Three services would be provided by the energy information system to overcome these obstacles:

- to provide examples of buildings for building operation

- to facilitate performance benchmarks for building operation

- to identify energy efficient operational patterns

Use case 3. A building owner involved in the renovation of a building

Users are building owners who can be private investors or public administrations. Typically, their knowledge of building energy efficiency would be lower than the one of users in previous cases. The goal of the owner is to improve the performance of a building by renovating it. To achieve his goal, it is necessary:

- to look for performance benchmarks to have an idea of possible improvements 
- to look for precedents of building renovations which can serve as models

- to be aware of the impact of the different options of the renovation of the building, in particular of the costs.

Nowadays, it is difficult to identify buildings that require renovation plans and to define appropriate actions to improve them. The missing information would be retrieved from the information system with these services:

- to provide examples of renovated buildings

- to facilitate performance benchmarks for building renovation

- to identify energy efficient design patterns

Use case 4. An energy consultant performing simulations at the design phase

The user is an energy consultant working at the design stage who has a better knowledge of building performance and systems compared to the users in previous cases. The goal is to provide the design team with guidelines and recommendations in order to achieve a low energy building. The consultant participates in the refinement of energy performance objectives, proposes strategies and detailed solutions, and informs the design team of the energy performance of the design solution supported by an energy simulation software. The fulfilment of these activities requires:

- to look for performance benchmarks to set design objectives and to compare design alternatives.

- to look for precedents and explain the reasons for their good performance to the design team.

- to study and explain the impact that design variables have on the energy performance of the building to the design team.

Although experts have easier access to the different information sources they need to carry out their consultancy, they still have to access large amounts of information with high level of detail to derive some conclusions from it. This activity is very time-consuming and constitutes a substantial obstacle for the consultancy business. These four services provided by the information system would help energy consultants in their task:

- to upload building energy simulations

- to provide examples of buildings for new building design

- to facilitate performance benchmarks for new building design

- to identify energy efficient design patterns

Based on these four use cases, a prototype of an energy information system has been developed using semantic web technologies.

\subsection{Creating an energy model}

To interlink the various data sources identified in the use cases, it is necessary to create a shared vocabulary that will enable services to identify the data that different users need and in the format they require in a particular context. Each of the available data sources and energy parameters have been analysed and classified and the relationships between them identified. This set of definitions constitutes an energy model that is formalized in a later stage as an ontology (21).

Creating a shared vocabulary requires the usage of standardised terminologies and of certain agreed definitions that facilitate the understanding among users of the vocabulary. For the SEíS energy model, we have used standard definitions proposed by previous research projects like Datamine (12) and by international ISO CEN standards (e.g. ISO 13790:2008). Energy experts and ontology engineers have done this work collaboratively. The result has been an ontology that describes entities and relations, data types and units from all data sources (22).

The SEíS information system uses semantic technologies to integrate various data sources from different applications operating at various stages of the building life cycle (Figure 3). The data sources encompass energy certificates, building descriptions, simulation data, energy monitoring, and climate data:

- Building energy certificates and simulation data from design and refurbishment phases collected by the Catalan Energy Institute (ICAEN). Data include building energy rating, consumptions, types of mechanical systems and geometric characteristics. From 1800 certificates available, we have included 200 certificates that contain simulation outputs in the dataset. Currently, relevant attributes such as consumptions and emissions are not included in this database. For these, approximated values have been calculated from studies of the Spanish building sector (9), and from standard values of national regulations (23) and European standards (24).

- Building monitoring data, such as those provided by the company Leako, which maintains a database of thermal consumptions for heating and hot water, water consumption and temperature for several buildings. This database does not include building envelope and equipment data.

- Geographical data collected by public institutes such as the Geographical Information National Institute (CNIG)(25) which are published in the Spanish gazetteer afterwards. The data include population, areas, elevation, or Universal Transverse Mercator (UTM) coordinate. Climate zones -fundamental for buildings energy performance analysis-were derived from the classification of Spanish Building Code (26).

\section{INTERACTING WITH A SEMANTIC ENERGY INFORMATION SYSTEM}

The semantically modelled energy related data and the services that they operate with are accessible to different user profiles through an on-line application (www.seis-system.org) which

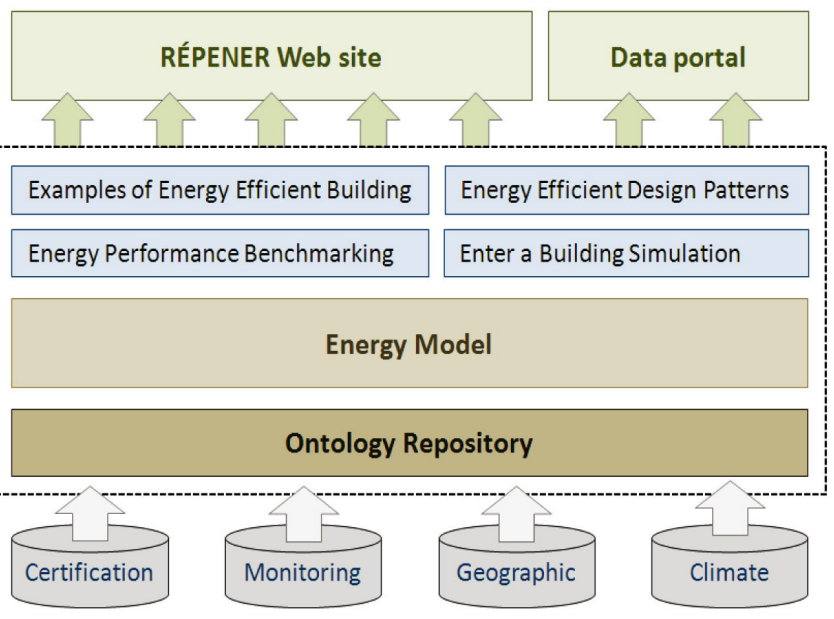

Figure 3. SEíS information system structure. 
has two front-end interfaces: a data portal where the integrated sources are shared with third-parties and the information system front-end which gives access to the energy services.

In this application, users with different profiles (Design Team, Facilities Manager, Building Owner, Energy consultant) can retrieve and upload data in interaction with the system and they can invoke services that operate with the data This represents the first step in the creation of a more comprehensive energy system with additional data and services.

At the start, users select their profile. In this way, they can have access to the implemented services that suit their activity level. Once a service is selected, the user provides further inputs (e.g. use and location) which are needed to identify the appropriate service. Explanations and comments guide users in their navigation through the information system. In this way, they can progressively reach the information they are looking for.

Based on the input data provided by the user, each service generates an output data from the available data sources. This background process requires: first, the transformation of the row data that the service requires from the original sources into a neutral standard (e.g. use of first heat generator - standard attribute of the energy model - may be obtained from the ICAEN data in function of specific data from this source: hot water system type; heating system type and joint generation of heating and hot water), and secondly, the triggering of specific processes to produce the expected output (e.g. a set of projects, a benchmark).

During these processes, SEíS services use the energy model to access the data they require. So far, four services have been implemented which suit the needs identified in the use cases described in the previous section. These services are constrained by the data sources available. In the future, new services can be added thanks to the open structure of the system.

\subsection{Implemented services}

The services actually implemented in the system are described next:

\section{$\underline{\text { Service 1. Examples of energy efficient buildings }}$}

This service searches for examples of efficient buildings based on the inputs Location and Use. A user may prioritise the Energy Uses and the Energy Performance Indicator that are relevant for the search. The outcome of the search is a ranking of buildings organized according to two groups of indicators: Energy (heating and cooling demand, total primary energy, $\mathrm{CO} 2$ emissions) and Indoor Space (time above and below comfort). The user can interact with the output by selecting a building to obtain specific information about it. This information is obtained from different databases and organized in four categories: building properties, performance, operation, and outdoor environment.

\section{$\underline{\text { Service 2. Performance benchmarks }}$}

This service elaborates benchmarks based on the inputs Location and Use. A list of indicators (Comfort, Demand, Consumption, Primary energy and Carbon Emissions) is displayed. Values are calculated for two types of building: "Efficient Buildings" and "All Buildings".

If the user is a building owner, the benchmarking service furnishes insights about to improve the performance in buildings that have been renovated. For both groups (most efficient and all buildings) the median value of each performance indicator is calculated. Bar graphs show each indicator values of before and after the refurbishment (Figure 4).

\section{Service 3. Energy efficient design patterns}

This service helps designers to identify patterns for energy efficient design that are derived from the data of the buildings accessed by the information system.

The inputs required by the service include Location and Use. In addition, the user selects an Energy Performance Indicator and the service determines the group of most efficient buildings which correspond to it. The differences between the most efficient buildings and other buildings are shown, and if a design variable is particularly relevant it is highlighted. This visualization helps, a user to easily identify which design variables are likely to have a greater impact on the design of an efficient building.

\section{Service 4. Building simulation results}

An energy consultant may use this service to upload the data of a building energy simulation. The information to upload is divided in five categories: Project Data, Building Properties, Outdoor Environment, Operation and Performance. The data uploaded will be assigned to the terms of the ontology thus ensuring the compatibility of the new data with the existing data.

Having uploaded the data of the building simulation, an energy consultant may rank it with other buildings available in the system, by accessing the service Examples of Energy Efficient Buildings. Alternatively, a user can compare the results of the building simulation with benchmarks by accessing the service Energy Performance Benchmarking.

While the benchmarks' calculation of all selected buildings is based on median values, that of the subset of efficient buildings is determined as follows. All selected buildings are ranked according to weighted values from different performance indicators. Then the top 30\% of the ranking are considered to be energy efficient buildings. In this case, we are applying the same rate as the one derived from the building energy certificates performed in Spain until September 2012. However, if this rate improves in the future (for example, if the objectives of Nearly-Zero Energy Buildings are reached) this percentage might be changed in the system.

\section{VALIDATION OF THE SYSTEM}

The information system has been tested with potential users in order to verify its value. The objectives of this validation process were to verify the strengths and weaknesses of the prototype and to identify the missing functionalities and future improvements. Six users representing the typical user profiles were invited to a working session:

- an architect specialized in sustainable building design

- an energy consultant specialized in building energy simulation 

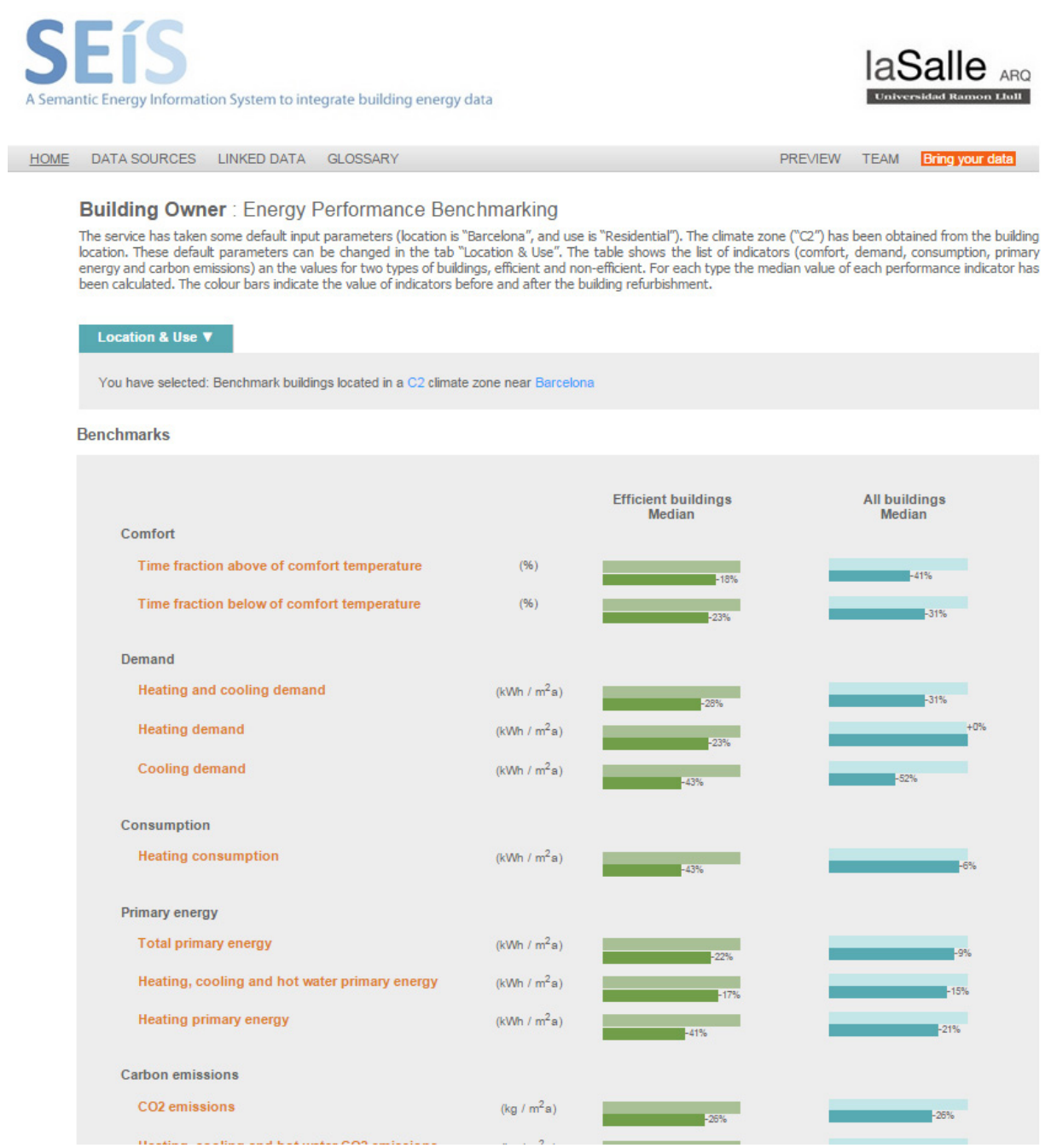

Figure 4. Performance benchmarks requested by a building owner.

- a public officer of the Catalan Institute of Energy, responsible for energy certificates and promoting energy efficiency in buildings

- a public officer of the Catalan Housing Agency involved in the development of related projects and the management of social housing

- a facility manager responsible for large tertiary buildings

- a technician from the Planning Permission Department of a local authority

In a joint introductory session, the information system was presented to the users and its purpose and functionalities discussed. Afterwards, they had an initial opportunity to interact with the interface to test its usability. Later, separate interviews were conducted to elaborate conclusions on individual basis. From the users' feedback, we could conclude that in the four use cases the information provided by the different services was considered as "relevant" or "very relevant". All of the users acknowledged the potential improvement that the energy system would bring to their current practices. However, they missed information on the construction and operational costs to evaluate the economic impact of the energy efficiency measures. For example, to figure out the investment necessary to achieve certain energy savings and to find out about the measures that are more cost-effective.

In addition, some shortcomings were detected in the evaluation. Firstly, the need to guarantee the quality of the data introduced in the system from different databases and users. Secondly, the need to motivate users to supply energy information which helps to develop the system further. And lastly, the necessity to increase the available information including the contact information of the stakeholders involved (design team, facility manager, etc.).

\section{CONCLUSIONS}

We have devised and implemented a methodology to create a semantic-based energy information system with the objective of interlinking multiple sources of data along the different stages of the building life cycle. The design of the system starts with the analysis of the current needs about energy information at the specific stages of the building life cycle and continues with the modelling of the interactions between users, data and the activities by means of use cases. Use cases encapsulate the specification requirements and the underlying energy model. The energy model is later formalized as an ontology that can be defined as a formal shared vocabulary that facilitates data access to users from different domains, operating at different phases of the building life cycle.

With this methodology, it has been possible to:

- summarize the main demands of energy information for different stakeholders and life cycle stages that are needed to improve energy efficiency in buildings 
- identify, relate, integrate and model building energy data obtained from different sources and formats

- apply energy expert knowledge to create new integrated data sets (and work with them), determine variables, indicators and units that are useful for different stakeholders

- take advantage of the experience gained from the analysis of the energy behaviour of buildings to create specific services for building design, operation and refurbishment

- make available some of the energy efficiency information (data) and knowledge to building stakeholders (data interpretation and guidelines) that is usually restricted to experts

The prototype system we have created -SEíS- gives insights into the benefits of providing access to energy information of the whole building life cycle. However, to increase the benefits of data accessing through this system, it would be necessary to substantially increase the amount of data available. For example, enhancing the data contained in existent energy certificates, having access to monitoring data, collecting information from energy building simulations and, especially, anticipating how to acquire data from energy certification of existing buildings that is not yet in force. Once a critical mass of information is reached, the use of a system like the one we have developed would contribute to the creation of a knowledge base that different stakeholders could use to obtain valuable information, helping them to make informed decisions in their respective domains.
In its future development, SEíS could integrate more data on energy performance of buildings, as well as on their geometric characteristics, construction systems, environmental conditions, and on the usage profile. This would expand the vocabulary and the relationships between the components of the energy model (i.e. of the ontology) and its current capacity to manage information would increase by incorporating user's experience giving rise to new services and capabilities.

Finally, we should also be aware of the risks that the use of an information system such SEíS may involve. First of all, without mechanisms to check the quality of data it is difficult to assure valuable outputs. Misleading outputs could result in the deterioration of building performance instead of improvements. An additional risk has to do with the service development. Complex procedures are embedded in the most advanced services, such as the "Energy efficient design patterns". The way that a service works might be difficult to explain to a user who might draw, in some cases, wrong conclusions from the outputs of the services.

\section{ACKNOWLEDGMENTS}

The work described in this publication has been carried out within the research project RÉPENER, co-funded by the Spanish National RDI Plan 2009-2012 (BIA 2009-13365).

\section{REFERENCES}

(1) Levine, M., Ürge-Vorsatz, D. (Coord. authors). (2007). Residential and commercial buildings. In B. Metz, O. R. Davidson, P. R. Bosch, R. Dave, L. A. Meyer (Eds.), Climate Change 2007: Mitigation. Contribution of Working Group III to the Fourth Assessment Report of the Intergovernmental Panel on Climate Change. Cambridge, United Kingdom and New York, NY, USA: Cambridge University Press.

(2) Hitchcock, R. J., Piette, M. A., Selkowitz, S. E. (1999). A Building Life-Cycle Information System For Tracking Building Performance Metrics. In Proceedings of the 8th International Conference on Durability of Building Materials and Components. Vancouver, BC, Canada.

(3) Gruber, T. R. (1993). Toward principles for the design of ontologies Used for Knowledge Sharing. In International Workshop on Formal Ontology. Padova, Italy.

(4) IntUBE. Intelligent Use of Buildings' Energy Information. http://cordis.europa.eu/projects/rcn/86722_en.html.

(5) Murray, M. C. (2012). Semantic Energy (PhD Thesis). Aberdeen: University of Aberdeen.

(6) Fay, R., Treloar, G., Iyer-Raniga, U. (2000). Life-cycle energy analysis of buildings: a case study. Building Research \& Information, 28(1): 31-41, doi: http://dx.doi.org/10.1080/096132100369073.

(7) Fullana, P. P., Frankl, P., Kreissig, J. (2008). Communication of life cycle information in the building and energy sectors. Nairobi, Kenya: UNEP.

(8) The Fraunhofer Institute for Building Physics. EeBGuide Project. Operational Guidance for Life Cycle Assessment Studies of the Energy Efficient Buildings Initiative. http://www.eebguide.eu.

(9) IDAE. (2011). Proyecto SECH-SPAHOUSEC. Análisis del consumo energético del sector residencial en España. Informe final. Madrid, Spain: IDAE.

(10) Economidou, M. (Ed.). (2011). Europe's buildings under the microscope A country-by-country review of the energy performance of buildings. Buildings Performance Institute Europe. http://www.europeanclimate.org/documents/ LR_\%20CbC_study.pdf.

(11) Blais, S. Parekh, A., Roux, L. (2005). Energy Guide For Houses Database - An Innovative Approach To Track Residential Energy Evaluations And Measure Benefits. In Ninth International IBPSA Conference. Montréal, Canada.

(12) Loga, T ., Diefenbach, N. (Eds.). (2009). DATAMINE. Collecting Data from Energy Certification to Monitor Performance Indicators for New and Existing buildings. Final report. Darmstadt, Germany: Institut Wohnen und Umwelt $\mathrm{GmbH}$.

(13) TABULA. (2009). Typology Approach for Building Stock Energy Assessment. http://www.building-typology.eu/.

(14) SIRENA. Regional Informative System for Energy and Environment. http://www.managenergy.net/resources/1391.

(15) Minergie-Home. (2013). http://www.minergie.ch/.

(16) REEEP, REN21. Clean Energy Info Portal - reegle. http://www.reegle.info/.

(17) Recheis, D., Bauer, F. (2012). Using LOD1 to Share Clean Energy Data and Knowledge. In Proceedings of the First European Data Forum, Copenhagen, Denmark. http://ceur-ws.org/Vol-877/paper2.pdf. 
(18) OpenEI. Energy Information, Data, and other Resources. http://en.openei.org/wiki/Main_Page.

(19) Cuchí, A., Wadel, G., Rivas, P. (2010). Cambio Global España 2020/50. Sector Edificación.

(20) León A. L., Muñoz S., León J., Bustamante P. (2010). Monitorización de variables medioambientales y energéticas en la construcción de viviendas protegidas: Edificio Cros-Pirotecnia en Sevilla. Informes de la Construcción, 62(519): 67-82, doi: http://dx.doi.org/10.3989/ic.09.045.

(21) Gruber, T. (1993). A Translation approach to portable ontologies. Knowledge Acquisition, 5(2):199-220, doi: http:// dx.doi.org/10.1006/knac.1993.1008.

(22) Nemirovskij, G., Sicilia, Á., Galán, F., Massetti, M., Madrazo, L. (2012). Ontological Representation of Knowledge Related to Building Energy Efficiency. In The Sixth International Conference on Advances in Semantic Processing (SEMAPRO 2012), (pp. 20-27). Barcelona, Spain.

(23) AICIA. (2009). Condiciones de aceptación de Procedimientos alternativos a LIDER y CALENER. Anexos. Madrid, Spain: IDAE. http://www.minetur.gob.es/energia/desarrollo/EficienciaEnergetica/CertificacionEnergetica/DocumentosReconocidos/OtrosDocumentos/Calificaci\%C3\%B3n\%20energ\%C3\%A9tica.\%20Viviendas/Cond_acept_anexos. pdf.

(24) ISO. (2008). ISO 13790: 2008 (E). Energy performance of buildings - Calculation of energy use for space heating and cooling. International Organization for Standardization.

(25) Instituto Geográfico Nacional. (2013). http://www.cnig.es.

(26) CTE. (2006). Código Técnico de la Edificación. Madrid, Spain: Ministerio de Fomento. 